\title{
INVESTIGACIÓN/RESEARCH
}

Recibido: 22/07/2012---Revisado: 27/09/2012 Aceptado: 13/12/2012---Publicado: 15/07/2013

\section{MIRADAS AL ANÁLISIS DE CUATRO MITOS VENEZOLANOS DESDE LA PERSPECTIVA DE LÉVI-STRAUSS DE LO CRUDO Y LO COCIDO}

Jenny Nohemí Fraile Velásquez ${ }^{1}$. UPEL-Instituto Pedagógico de Miranda José Manuel Siso Martínez. Caracas. Venezuela

jennyfraile@yahoo.com

\section{Resumen}

El siguiente artículo presenta una mirada de cuatro mitos sobre el origen del fuego de cuatro etnias venezolanas a la luz de lo propuesto por Lévi-Strauss en Lo crudo y lo cocido. Se trata de una investigación documental con análisis de contenido y cuyo objetivo general fue analizar mitos de etnías venezolanas aplicando el método propuesto por Lévi-Strauss y luego comparer con algunos de los mitos brasileños presetnados por este antropólogo en Mitologías I. Luego del análisis y la comparación se llegó, entre otras, a las siguientes conclusiones: (a) se aprecian más o menos los mismos elementos y personajes en los mitos de etnias venezolanas que los que están presentes en los mitos de etnias brasileñas, (b) cuando es un personaje femenino quien guarda el secreto del fuego por lo general lo hace dentro de su cuerpo, en tanto que si es un personaje masculino el conocedor del fuego lo tiene guardado fuera de su cuerpo, (c) en todos los mitos quien divulga el conocimiento del fuego lo hace tras haberlo robado, hurtado, siempre con el uso de alguna treta o engaño.

Palabras clave: Mitos de origen del fuego- etnias venezolanas- análisis de mitos.

\footnotetext{
1 Autor correspondiente:

Jenny Fraile Velásques: es egresada del Instituto Pedagógico de Caracas como profesora en Educación Integral, es Especialista en Gerencia Educativa de la Universidad Santa María.

Correo: jennyfraile@yahoo.com
} 


\title{
LOOKS TO THE ANALYSIS OF FOUR MYTHS VENEZUELAN PERSPECTIVE LEVI-STRAUSS'S THE RAW AND THE COOKED
}

\begin{abstract}
This article presents a look of four myths about the origin of the fire of four Venezuelan ethnic groups in the light of what was proposed by Lévi-Strauss in The Raw and the Cooked. This is a documentary research and content analysis whose overall objective was to analyze myths Venezuelan ethnic groups using the method proposed by Levi-Strauss and then comparer with some myths Brazilian anthropologist presetnados this Mythologies I. After the analysis and comparison was reached, among others, to the following conclusions: (a) are seen more or less the same elements and characters in the myths of Venezuelan ethnic groups that are present in the myths of Brazilian ethnic groups, (b ) when a female character who holds the secret of fire usually does inside your body, whereas if a male character as the knower of the fire is kept out of your body, (c) in all myths who disclose knowledge of fire after stealing it does, stolen, always using trickery or deceit.
\end{abstract}

Key words: Myths of origin of the fire-ethnic myths Venezuelan-analysis.

\section{INTRODUCCIÓN}

Pensar en el ser humano parece que llevara de manera indiscutible a asociarlo a hechos culturales, a ver como éste en su devenir ha ido influyendo en su entorno ajustándolo a su conveniencia, a su nivel de desarrollo. En el proceso evolutivo que permitió la diferenciación de una de las especies de primates superiores en homínidos y de éste el paso a hombre. En esta evolución hay dos hechos antropológicos que lo marcan y diferencian de los demás animales y son, indiscutiblemente, la palabra y la cocina.

Al respecto señala Cordón (1979) que "la palabra ha supuesto un cambio radical en la naturaleza del homínido (su transformación cualitativa en hombre)" (p.109). El homínido que descendió del árbol, se traslado en busca de nuevas formas de alimentarse, que no sólo respondía a la necesidad biológica de ingerir alimentos a fin de mantener la energía y desplazarse en su territorio. Inicio un proceso de diferenciación de qué se puede y qué no se puede comer, los adultos instruirían a los más jóvenes trascendiendo el hecho de comer para subsistir. Luego con el descubrimiento del fuego, que le sirvió de mecanismo de defensa contra otras especies animales que le asechaban determinó un cambio cualitativo que definitivamente marcaría la distancia del homínido de los demás animales. 
Para Cordón (Ob.cit) "el hambre es, junto al fuego, otra condición indispensable para el descubrimiento y arraigo de la actividad culinaria" (p.112) y el cocinar, procesar sus alimentos obligaría al surgimiento de la palabra, para a través de ésta planificar la caza, la recolección que luego darían lugar a la domesticación de algunas especies y al surgimiento de la agricultura; hechos que además marcarían la diferencia entre las culturas nómadas y las sedentarias con todos sus roles y diferenciaciones sociales, que en definitiva marcarían las características definitorias de las civilizaciones, de la cultura.

El desarrollo de la sociedad humana, la invención culinaria, el surgimiento de la palabra y la modificación de toda la conducta, asentamiento y costumbres del homínido devenido en hombre es lo que llamamos cultura; ya que ésta, según Montanari (2004) "se encuentra en el punto de intersección entre la tradición y la innovación" y sin duda alguna la alimentación ha generado todo un conjunto de tradiciones e innovaciones que han permitido la invención de diferentes técnicas, utensilios y modos de vida que distancian al hombre del resto de los animales.

La diversificación de la forma de obtener los alimentos, sus preparaciones, las tradiciones culinarias también influyeron en la distinción de las clases sociales en todas las épocas y civilizaciones. La posesión de la sal, especies, azúcar o miel marcaba la distancia entre una clase social y otra, tanto en las sociedades europeas, asiáticas, africanas como americanas. Cartay (1992) en Historia de la alimentación del nuevo mundo, reporta como la dieta, el consumo de diferentes alimentos distinguían los diferentes estratos en sociedades como la azteca.

Es entonces, según lo expuesto hasta el momento, lícito sostener que el hecho culinario, en palabras de Cordón ha hecho al hombre y ha definido no sólo el surgimiento de la palabra sino de todo un conjunto de condiciones, costumbres, tradiciones que permiten ver en ella un evento cultural que da pie para ahondar, profundizar en cómo ésta se ve reflejada en la palabra, en sus combinaciones y en la comunicación cotidiana que permite trasladar expresiones de la cercanía del fogón a otros contextos redimensionando su significado.

Es esta función cultural de la cocina marcada por el conocimiento del fuego el tema que se abordara en las páginas subsiguientes, a partir del trabajo realizado por el antropólogo francés Claude Lévi-Strauss, y su revisión de mitos de etnias brasileñas, en torno a los mitos sobre el origen del fuego, se compararán algunos de ellos con los de tres etnias venezolanas (warao, yekuana y guajira)

\section{MIRADA A LÉVI-STRAUSS}

La mirada que tiene Lévi-Strauss del mundo la percibe desde la geología, el marxismo y la visión freudiana por lo que la interpretación que realiza de la simbología de los mitos permite elaborar un entramado entre la región y sus formas, las relaciones sociales y la sensualidad allí contenida, ya que busca interpretar la realidad no solo desde lo aparente, observable, medible sino que busca indagar en lo oculto, en los secretos que guardan "los cortes transversales" y develan las estructuras y las 
relaciones entre lo racional y lo sensible o como lo propone Shütz (2008) la realidad y la imaginación, sin que una niegue a la otra, por el contrario, se asume el nivel de realidad que cada una posee.

Para Lévi-Strauss la misión de su trabajo de investigación, el cual sirve de sustento al trabajo que se presenta, consiste en tratar de descifrar el código de las relaciones internas que se dan en el hecho lingüístico. En pocas palabras, este antropólogo, pretende develar todas las relaciones presentes en los mitos, emplea para ello un método basado en la analogía en la que el lenguaje, los ritos, el arte, la economía, la religión, el hecho culinario son sistemas de signos entre lazados en y con las palabras. Es una constante en el trabajo de este francés la conexión entre el universo del discurso y la realidad no verbal, entre el pensamiento y las cosas, y entre la significación y la no significación. Esta visión encuentra su eco en la propuesta de Shütz (ob.cit) ya que una conmoción hace percibir cuando la imaginación da paso a la realidad efectuante en la que sí se ejerce una influencia o cambio en el mundo.

Según Paz (1992) Lévi-Strauss al guiar sus estudios en la combinación de los propuestas de Marx, Freud y la geología aprende a "explicar lo visible por lo oculto, o sea, a buscar la relación entre lo sensible y lo racional" (p.12), como se indicara en líneas precedentes. De allí que sobre lo expuesto por Durkeim acerca de cómo la realidad social está compuesta por una superposición de fenómenos unos relacionados con otros, lo cual sirve de marco para entender a través de los mitos las relaciones sociales y culturales.

Define Paz (ob.cit) como cultura de una sociedad al "sistema total de relaciones que engloba tanto al aspecto material como al jurídico, religioso y artístico"(p.14), en tanto que Lévi-Strauss la concibe, desde la influencia de Marx y de la lingüística, y es producto de la sociedad como un conjunto de signos como una estructura, como un sistema de comunicación (p.14), expresado este sistema de signos en los mitos, en cuya estructura se puede observa la repetición de ciertos patrones, de ciertas relaciones socioculturales, temas, vínculos en los mitos de una misma región e incluso de diferentes regiones y épocas; habla pues Lévi-Strauss de un pensamiento mítico en espiral-universal.

Otro aspecto importante del trabajo de este antropólogo francés reseñado por Paz (ob.cit) es la notable influencia de la perspectiva lingüística presente en sus miradas, por lo que establece una analogía entre el mito y la lengua-lenguaje-habla. El mito es al mismo tiempo habla y lengua, ya que alude a lo que pasó y es un decir irrepetible; al mismo tiempo es lengua, una estructura que se actualiza cada vez que se vuelve a contar.

Es en esta relación estructural en la que aparecen los imitemas, que los equipara a los sememas, los cuales en sus diferentes combinaciones deben originar mitos así como los fonemas producen sílabas, palabras, textos. Gracias a los mitemas los mitos son habla y lengua, tiempo irreversible (relato) y reversible (estructura), diacronía y sincronía (p.29). 
Es precisamente esta estructura mítica la que genera cierta recurrencia de temas y motivos, dentro de estos elementos recurrentes se dejan ver las oposiciones vidamuerte, agricultura-caza, y los términos de mediación entre las proposiciones. Explica Paz

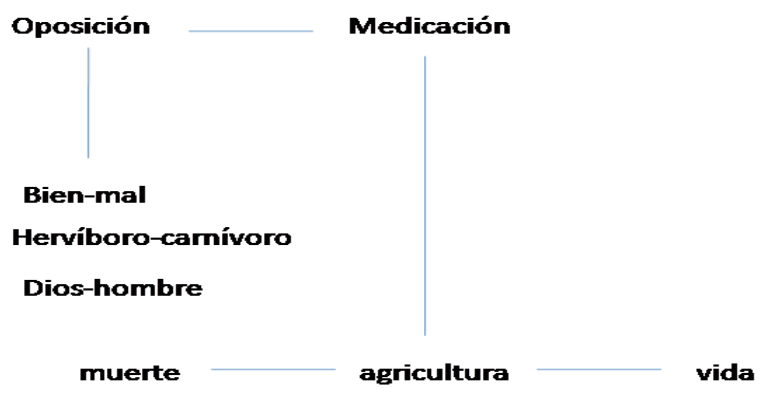

(ob.cit) que "la mediación entre herbívoros y carnívoros surge con la aparición de coyotes y zopilotes (zamuros) que se alimentan tanto de carnívoros como de herbívoros pero al igual que estos últimos no son cazadores. Dentro de la fórmula develada que compone al mito se encuentran:

Gráfico 1. Fórmula inicial para el abordaje del análisis de los mitos. Interpretación de la autora del trabajo de Lévi-Strauss en Antropología Estructural (1968).

El personaje o acción que sirve de mediación entre los opuestos puede variar, es decir, uno positivo puede transformarse en negativo, ya que su función es permitir "resolver o trascender la oposición" (p.36). Es entonces, necesario establecer que ninguno de los elementos o personajes de los mitos tiene significancia por sí mismo, sino en la relación, en el contexto el cual enmarca define su significado.

El método que propone el antropólogo francés y del cual se distancia Octavio Paz (p.37) expresando que éste:

"Prohíbe un análisis del significado particular de los mitos: por una parte, piensa que esos significados son contradictorios, arbitrarios $y$, en cierto modo, insignificantes; por la otra, afirma que el significado de los mitos se despliega en una región que está más allá del lenguaje"

Sin embargo, ya se ha dicho, que esta relación entre las oposiciones con la influencia de la mediación permiten establecer un pensamiento mítico que trasciende la región y la época, de tal forma que se consiguen elementos similares en estructuras míticas griegas en los mitos indígenas como en los africanos, aun y cuando ni comparten la 
misma región geográfica ni mucho menos el tiempo, ni ningún otro dato sociolingüístico.

En "Lo crudo y lo cocido" este antropólogo presenta de cerca de 200 mitos, dada sus variaciones de un grupo étnico a otro, las incorporaciones que hacen la mediación y por ende la resolución de la posición planteada varía. Al revisar este trabajo y leer los mitos de esos grupos indígenas brasileños se hacía difícil no evocar las versiones que de los mismos mitos se tienen en las etnias venezolanas, es por ello que partiendo de la premisa propuesta "el mito crece como una espiral la nueva versión lo modifica, y al mismo tiempo lo repite" (p.38); es que se plantea este trabajo en el cual se incluyen las versiones que existen en los grupos originarios de Venezuela de algunos mitos estudiados por Levy-Strauss en Brasil.

Esta relación entre los grupos indígenas brasileños y venezolanos podría confirmar o suministrar más datos para la hipótesis que apuesta a la unidad de la civilización americana, o al menos, refleja, desde la perspectiva de quien escribe, el manejo de un mismo imaginario entre los pueblos de la América de Sur, o al menos entre estos dos vecinos.

El otro centro de interés que motiva a la investigadora a la revisión del material "Lo crudo y lo cocido" es el cómo en éste se muestra la actividad en torno a la cocina como un hecho, develado en los mitos, que sirve de puente entre la naturaleza y el ser humano, funge como mediación entre diferentes pares opuestos como: lo crudo y lo cocido, la endogamia y la exogamia, vida y muerte, naturaleza y cultura. Resumida esta idea por Octavio Paz (ob.cit) "Toda frase dice algo que puede ser dicho de otra frase, todo significado es un querer decir que puede ser dicho de otra manera" (p.54). Para Paz la obra de Lévi-Strauss "tiende un arco que une dos paisajes contrarios: la naturaleza y la cultura" (p.75), es justamente allí en donde incide el interés por esta obra referente en cualquier estudio antropológico, y aunque esa no es la orientación del trabajo, sirve de base para observar elementos culturales de nuestros pueblos originarios y cómo éstos se relacionan a través de la estructura de los mitos con otros grupos indígenas de la región, y claro está, cómo se ve influenciada la cultura hecha comida desde los tiempos precolombinos hasta los nuestros; desde que la tierra era nuevecita y el hombre hablaba como el jaguar, hasta hoy que anda en un jaguar.

Esta forma de pensamiento plasmado en los mitos sienta las bases de una relación entre lo que se siente y lo que se vivencia. Según Levi-Strauss (1968) "el estudio de los mitos nos conduce a comprobaciones contradictorias" (p.187) y descubrir elementos que se repiten "de un extremo a otro de la tierra" (p.188). En líneas precedentes se nombraron algunos de los pares opuestos que se encuentran en la estructura mítica, sin embargo,

"La contradicción no fue resuelta hasta el día en que se percibió que la función significativa de la lengua no está ligada directamente a los sonidos mismos, sino a la manera en que los sonidos se encuentran combinados entre si". (p.188) 
Es decir, el mito pertenece al discurso, a la lengua y ésta pertenece al dominio de un tiempo irreversible que ciñe su estructura y forma de organización, así como su empleo por hablantes lo que constituye la dimensión estadística (número de hablantes, variaciones lingüísticas). Un mito se refiere siempre a acontecimientos pasados: "antes de la creación del mundo" o "durante las primeras edades" o en todo caso "hace mucho tiempo". Pero el valor de un mito proviene de estos acontecimientos, que se suponen ocurridos en un momento del tiempo, forman también una estructura permanente. En la que se refiere simultáneamente al pasado, presente y al futuro. (p.189)

Podría resumirse este aspecto:

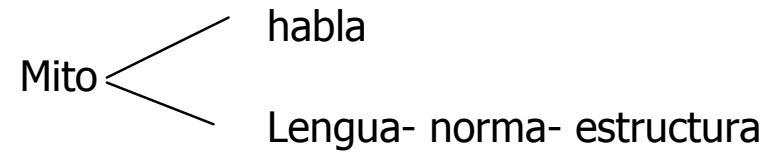

Se podría definir al mito como ese modo del discurso en el que el valor de la fórmula tiende prácticamente a cero (p.190), es decir según lo propuesto por Lévi-Strauss la sustancia del mito no se encuentra en el estilo, ni en el de redacción, ni en la sintaxis, sino en la historia relatada, en sus personajes, relaciones, mediaciones, contrarios, variaciones. Es decir, en este ámbito el mito es lenguaje, entendido este como forma de comunicación.

Del trabajo presentado por este autor en 1968 se puede, entonces, definir al mito como un: a) ente verbal que ocupa en el domino del habla un lugar comparable al del cristal en el mundo de la materia física, b) medio por el cual una sociedad expresa amor, odio, venganza, c) modelo lógico para resolver una contradicción, d) instrumento para explicar fenómenos difícilmente compresibles a través de una interpretación bien sea cosmológica-naturalista, o sociológica-psicológica.

En el siguiente esquema la autora de este trabajo resume lo presentado por el francés en relación al mito, ya que éste conduce a comprobaciones contradictorias en función de los elementos que le integran y le caracterizan. 


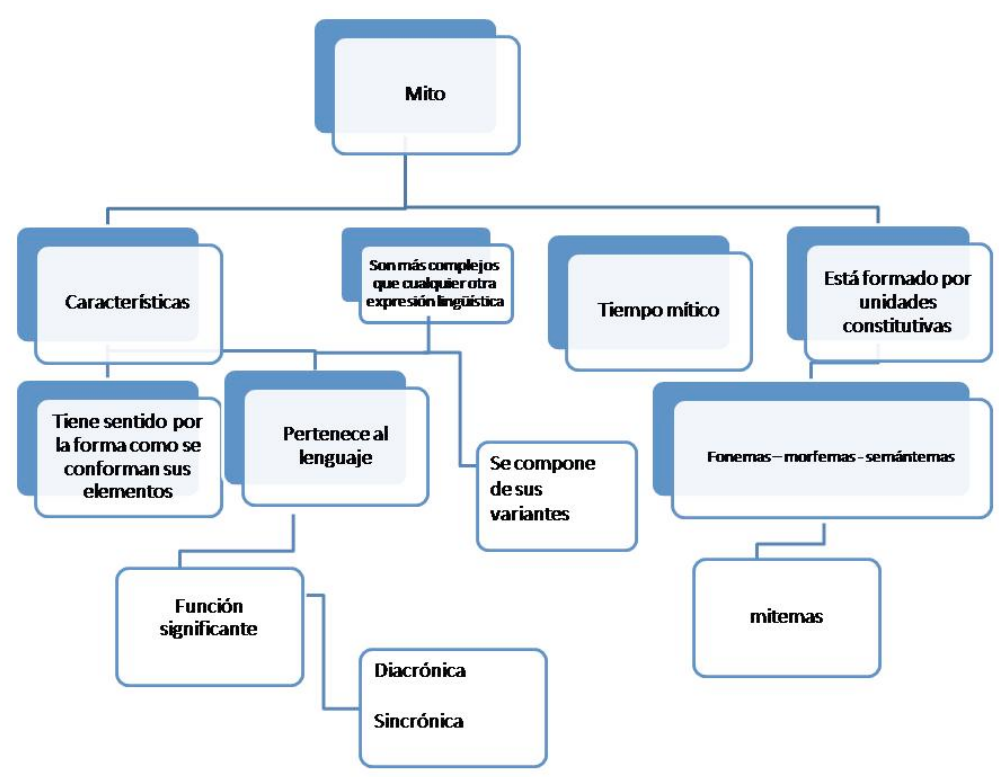

Gráfico 2. Resumen teórico sobre el mito y sus características. Elaboración de la autora.

Según lo propuesto por Lévi-Strauss (ob.cit) el mito es una construcción lingüística compleja representada por sus mitemas que son superiores en el nivel de significación a los semantemas; en relación al tiempo mítico se tiene que éste al igual que la estructura se desarrolla en espiral, lo que hace que haya tenido vigencia en el tiempo en el cual fue contado-escuchado por primera vez tanto como cuando es retransmitido en la actualidad, es decir, trasciende su espacio y su tiempo, por lo que su significación es tanto diacrónica como sincrónica.

El método de análisis de los mitos propuesto por este autor consiste en separar en macroproposiciones los temas subyacentes en la historia y con ellas deconstruir la historia en sus acciones separadas en columnas (una por cada tema) ordenadas como se escribe y lee en nuestra lengua, es decir, la primera acción del primer tema a la izquierda y las siguientes acciones de los siguientes temas hacia la derecha.

En lo concerniente al trabajo que se presenta se analizarán mitos de etnias venezolanas de los cuales se piensa tienen la misma estructura o se pueden considerar variantes de algunos de los mitos analizados por Lévi-Strauss de las etnias brasileñas y que hacen referencia a la caza- agricultura, cocido - crudo, vida muerte. Señala el etnólogo francés que:

"Si este método de análisis estructural se aplica sistemáticamente, conseguimos ordenar todas las variantes conocidas de un mito en una serie, que forma una especie de grupo de permutaciones y donde las variantes colocadas en ambas extremidades de la serie ofrecen, una con respecto de la otra, una estructura simétrica pero invertida". (p.204) 
Este análisis estructural permite además extraer las ideas básicas del pensamiento mítico que se repite y se crece en esa suerte de espiral descrito por este autor. Estas operaciones del pensamiento que son develadas a través del análisis estructural propuesto por Lévi-Strauss se resume en el siguiente esquema.

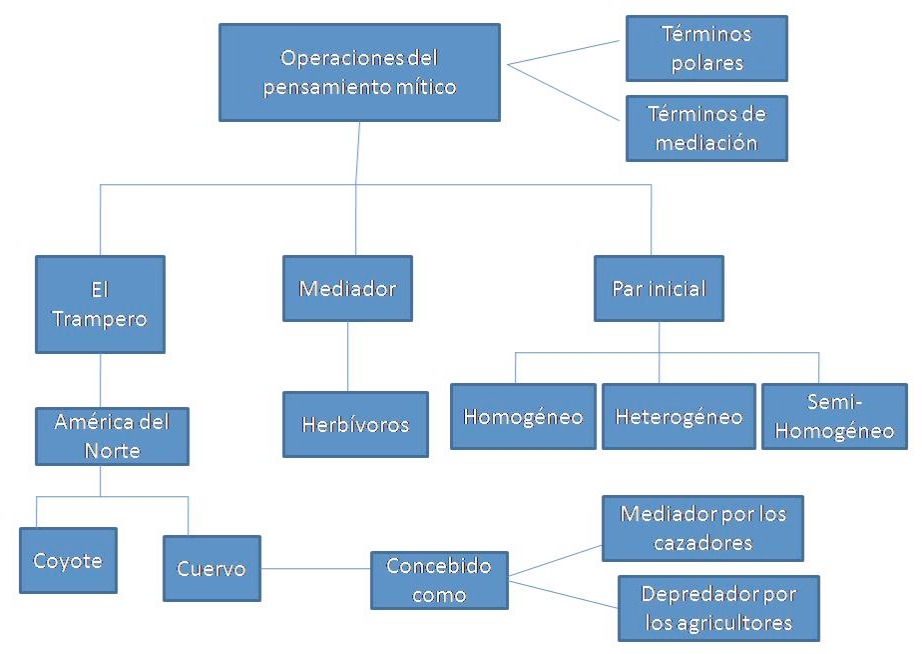

Gráfico 3. Operaciones del pensamiento mítico según Lévi-Strauss. Elaboración de la autora

Para Lévi-Strauss el análisis de los mitos, aparte de cómo se indicó realizarse en columnas y en base a macro proposiciones, sugiere que el pensamiento mítico opera en función de la relación de términos polares a través de una mediación que surge en el par inicial (por lo general opuesto): par inicial --- primera triada --- segunda triada; siempre y cuando ocurran "dos traumatismos"(p.208) que permitan que uno de los términos de la primera triada sea sustituido por su contrario.

Es decir, que la estructura del mito que propone se caracteriza por los siguientes rasgos: a) se puede leer e interpretar sus datos organizados en columnas, filas de izquierda a derecha, b) su interpretación puede ser sincrónica o diacrónica, c) tiene una estructura múltiple que se evidencia en la repetición, d) se desarrolla en espiral, desde el origen hasta la más distante de sus variantes en la cual se agota "el impulso intelectual que le ha dado origen" (p.209)

El método de análisis de Lévi-Strauss propone también la resolución de la relación mito-ritual, siendo el primero es metalenguaje y el segundo paralenguaje. En esta confluencia se enriquece el estudio simbólico que se puede realizar a partir del mito y de las relaciones, del hecho cultural subyacente en la historia y en los temas que éste trata.

\section{MIRADA A LOS MITOS DE ORIGEN DEL FUEGO}

\subsection{Venezolanos}

\subsubsection{Jekunu Arotu (el señor del fuego) -guarao-}


Dos hermanos estaban en la montaña buscando colmenas. Cuando el hermano mayor tumbaba los árboles, aconsejaba al otro:

- No te acerques, hermano, que puede caerte el árbol encima.

Pero el muchacho era porfiado y no le hacía caso; hasta que uno de los árboles le cayó encima y lo mató.

El hermano, dejando colmenas, se echó el cadáver al hombro y se dirigía con él a cierto lugar del monte para enterrarlo.

Mas a medio camino se cruzó con él una muchacha de la que se enamoró el indio.

Le dijo ella:

- Te pondrías bravo y lo mataste. ¿No?

- No digas tal cosa mujer- protestaba el indio-. Yo decía que se apartase; pero él no hacía caso, porque era porfiado, y al caer uno de los árboles lo alcanzó una rama.

- Después de haber enterrado al muerto los dos, se casaron. Mas ya en camino la mujer se enfadó con el marido y le dijo:

- Porque mataste a tu hermano, por eso no te quiero. ¿Por qué me has de obligar a ser tu mujer? Se lo diré a los indios.

- Por la noche se huyó a la ranchería inmediatamente, donde refirió a los indios que aquél había matado a su propio hermano y que a ella la quería obligar a ser su mujer.

- Por eso me escapé- dijo finalmente.

- Has hecho bien- le contestaron los indios-. Permanece en nuestra compañía, pues eres de nuestra familia. Aquí estarás segura.

- Después de algunos días emigraron los indios, yendo a establecerse a Nabakojoida, lugar que está por las tierras del Merejina.

- Al llegar dijeron a los indios:

- Venimos a establecernos entre vosotros, porque un indio que mató a su propio hermano, anda detrás de nuestras hijas para casarse con alguna; $y$ nosotros no queremos que pertenezca a nuestra familia.

- Eso está muy bien hecho- respondieron los del lugar-; ya desde ahora podéis quedaros con nosotros y vivir aquí tranquilos.

- Poco tiempo después recién venidos se internaron por la montaña, encontrándose con Jekunu Arotu, El dueño del fuego.

- Véngase a mi casa - les dijo Jekunu Arotu-. Aquí no ha de pasarles nada malo.

- iNo vayáis!- les gritaba uno de los indios-. Os vais a morir todos...

- Jekunu Arotu insistía:

- Venid sin cuidado; aquí lo pasaréis estupendamente.

Los indios entraron en la casa de Jekunu Arotu y éste los metió en el fuego y lo mandó avivar.

- iVeréis qué bien vais a estar! no tendréis nada de frío... 
Cuando el fuego comenzaba a levantar llama, cayó dentro un trozo del Najamutu o firmamento.

- iAhora sí arderá bien!- dijo Jekunu Arotu...

En efecto aquel pedazo de cielo avivó la llama. Los indios metidos en el fuego, gritaban sin consuelo.

- iAy!, iay!, iayyyy!... iQuítanos del fuego, Jekunu Arotu, que no queremos morir abrasados!

Pero Jekunu Arotu los animaba de otra manera:

- Gritáis de vicio, hermanos... ipero si ahí estáis tan bien...!

La voz de la india sobresalía entre la de los otros. Mas a los pocos minutos estaban ellos convertidos en carbones. Después de esto, el fuego se escondió debajo de la tierra y el pedazo de Najamutu se subió al firmamento y refirió por allá lo que en la tierra había visto. Como la gente se moriría al meterse dentro del fuego y como todo aquello de allá es muy pequeño comparado con el firmamento. Desde esa fecha el fuego quema a la gente y los indios tienen buen cuidado de no meterse en él.

\begin{tabular}{|l|l|l|l|l|l|}
\hline Personajes & Par inicial & Mediador & Héroe & Oposición \\
\hline Humanos & $\begin{array}{l}\text { No } \\
\text { humanos }\end{array}$ & $\begin{array}{l}\text { Hermanos } \\
\text { recolectores } \\
\text { Arotu }\end{array}$ & & & $\begin{array}{l}\text { Vida-muerte } \\
\text { Cielo-tierra }\end{array}$ \\
\hline $\begin{array}{llll}\text { Indios } \\
\text { Hermanos, mujer, } \\
\text { familia }\end{array}$ & & & & \\
\hline
\end{tabular}

\subsubsection{Jecunu. El fuego. Su origen. Guarao}

Aguajabara Jecunu Equida, Jocoji Ajeraguaitu. Al principio no había fuego; en cambio el sol era abrasador y con él preparaban los indios la YURUMA y asaban el pescado.

Pero descubrieron que en una ranchería había una vieja que en la noche, cuando dormía, ponía debajo del chinchorro un carbón encendido.

Una noche un indio intentó cogerle ese tizón a la vieja y para ello se fue caminando poco a poco a donde ella estaba acostada. Cuando ya se lo iba a coger, la vieja se dio cuenta, se levantó, cogió el tizón y lo tragó.

El indio dejó tranquila a la vieja y a la noche siguiente intentó nuevamente cogerle el tizón, pero tampoco lo pudo conseguir. Esa vieja tragaba el tizón y llevaba el fuego dentro de ella.

Un día salieron casi todos los indios de la ranchería a buscar la fruta llamada MUJI. Regresaron cargados de esa sabrosa fruta y le dieron parte a la vieja que se había quedado en casa. Como ella nunca la había comido, al probarla decía: qué fruta tan 
sabrosa, ¿por qué no me traéis más? Dijéronle los indios; esa fruta es muy escasa, ven con nosotros otro día a buscarla.

Al poco tiempo volvieron al monte los indios a buscar la fruta y la vieja también fue con ellos. Llegaron al árbol que la produce y el indio que se subió arriba le dijo a la vieja: ponte debajo del árbol para cuando yo tire las frutas puedas coger en abundancia. Subió el indio más arriba y la vieja se puso debajo del árbol, en espera de la fruta tan sabrosa. El árbol le cayó encima a la vieja. Como era tan pesado, al aplastarla, la vieja se reventó y salió de ella una gran llamarada.

Este fuego que salió de la vieja es diferente a todos los demás. Todos los otros fuegos se apagan; pero el fuego que sacan los indios del palo jimareju ese nunca se apaga, porque es el fuego que salió de la vieja. De esa manera los guaraos tuvieron fuego.

\begin{tabular}{|l|l|l|l|l|l|}
\hline Personajes & Par inicial & Mediador & Héroe & Oposición \\
\hline Humanos & $\begin{array}{l}\text { No } \\
\text { humanos }\end{array}$ & Vieja-indio & árbol & indio & $\begin{array}{l}\text { Vida-muerte } \\
\text { Frío-calor }\end{array}$ \\
\cline { 1 - 5 } $\begin{array}{l}\text { Vieja } \\
\text { Indio }\end{array}$ & & & & \\
\hline $\begin{array}{l}\text { Indios de la misma } \\
\text { aldea }\end{array}$ & & & & \\
\hline
\end{tabular}

\subsubsection{Kawao- yekuana}

Antiguamente los hombres no conocían el fuego. Comían su comida cruda.

Una mujer era dueña del fuego. Lo escondía en su barriga, no lo mostraba a nadie, ni siquiera a su marido. La mujer se llamaba Kawao: se cambiaba en rana cuando quería. Manuwa era el nombre de su marido; cuando salía a cazar, se cambiaba en jaguar, comía carne de gente.

Kawao conocía el secreto: cocinaba sabroso, como ahora nuestras mujeres. Tostaba yuca, mañoco, casabe, sancochaba frutas, asaba carnes; cuando lo hacía, se escondía. Esperaba que Manuwa saliera de cacería. Cuando estaba sola, abría la boca, sacaba fuego de su vientre, de prisa escupía el fuego debajo de la comida; luego sacaba la lengua, se tragaba aquel fuego otra vez. Ahora, llegaba el marido: su comida estaba lista.

Cuando llegaba preguntaba: Él no sabía.

- ¿Cómo hiciste?

- Con el calor del sol - contestaba la mujer- Pongo la comida al sol. Así nada más.

- Bueno- decía aquel jaguar. Era ingenuo, se dejaba engañar por su mujer.

El día que mataron a Hui 'io, madre del agua, la rana Kawao encontró las dos huevas de peces. Estaban abandonadas en la ribera: - Llévatelas- dijo su marido. - Buenocontestó ella, y se las llevó a casa.

Ella quería empollarlas para tener hijos. Él también quería tener hijos para comérselos. 
Cuando llegó a casa, ella metió las huevas cerca del fogón. Había un fogón secreto; allí soplaba su fuego. Con el calor de aquel fuego, se abrieron las huevas. No fueron peces los que nacieron, fueron muchachos. El mayor se llamaba Shikié'mona, el menor: Iureke.

Fueron dos hombres poderosos. Cuando nacieron, rápido crecieron. Enseguida caminaron, hablaron, comieron. Ya no eran niños. Eran hermanos de los peces, pero se veían como gente. Salieron de Huehanna, junto con los peces. La rana Kawao los halló, los adoptó.

- Soy vuestra madre- les decía. No les contó la historia como era, la de su madre, la de la muerte de su madre.

Eran turbulentos, impertinentes. Corrían, gritaban, jugaban, se peleaban, armaban griterío; hacían preguntas y preguntas; molestaban; cambiaban sus formas a cada rato. Para divertirse engañaban a la gente. Ahora como muchachos, ahora como peces, luego como grillos, luego como cucarachas. Se burlaban de la mujer Kawao; no obedecían. Parecían cuatrocientos muchachos metidos en la casa, y sólo eran dos.

Les gustaba andar en el río.

- Eso no está bien- dijo Manuwa-. Los peces van a hablar, les van a decir la verdad.

- Kawao, dijo: - Bueno. Voy a prohibirles que se bañen.

- Cuando volvieron, les dijo: - No quiero que vayan al agua.

- Bueno madre - dijeron-, no volveremos.

- Ahora pidieron su comida. Kawao los mandó fuera a jugar.

- Quiero estar sola para cocinar.

- Bueno - dijeron- nos vamos- pero se quedaron.

- Luego dijeron. - dinos cómo haces.

- Con el calor del sol- contestó.

- No puede ser- dijeron- con el calor del sol, no puedes. Dinos ahora la verdad.

La mujer se puso brava, los echó de casa: - Ahora os voy a castigar, no os daré comida.

Entraron por otra puerta: - Danos casabe- decían- dinos cómo lo haces.

Kawao los echó a palos.

Cuando salieron, saltaron al agua, diciendo: - Bueno, no volveremos. Bueno, no volveremos.

Entre los peces se metieron, nadando como peces. Llegaron a una casa grande en el fondo del río. Llamaron: nada. Nadie contestó.

- Esta casa está vacía- dijeron.

Ahora entraron. 
- Casa bonita - dijo el mayor.

- Me parece que la conozco- contestó el otro.

Hallaron chinchorros; se acostaron a dormir. Durmiendo, soñaron. Vieron a Hui 'io en sueño.

La gran serpiente decía: - Esta es mi casa, vuestra casa. Soy vuestra madre. Vuestro padre es Wanadi. Os han engañado. Aquella casa no es de vosotros. La rana no es vuestra madre, el jaguar no es vuestro padre. Ellos me han matado, me han comido. Ahora vivo en el cielo. Sólo en sueños os hablo. Tened cuidado con el jaguar: os quiere comer. Antes tenéis que matarlo.

Así soñaron los dos muchachos gemelos cuando se durmieron en el lecho del río, casa de Hui 'io, su madre.

Cuando despertaron, hallaron una totuma con aceite de caruto. La cogieron; soñaron otra vez.

- Esta es mi totuma, mi shimi de caruto para pintarme. Si la botáis, los ríos saldrán de madre, mucha agua cubrirá la tierra, ahogaréis la gente. Muchísima fue la gente que vino a matarme. De todas partes llegaron, hasta el más pequeño. Todos me comieron.

Despertaron otra vez aquellos muchachos: - Bueno- dijeron-, un día vengaremos a nuestra madre. Inundaremos toda la tierra, vamos a hogar toda la gente. Volveremos acá a buscar la totuma. Ahora la dejaron tranquila, escondida. Salieron nadando, diciendo.

- Vamos a casa del jaguar y de la rana. No son nuestros padres. Nos engañaron. Vamos a castigarlos por la muerte de nuestra madre.

En su camino hallaron una laja. Allí salieron, descansaron, como muchachos otra vez. Sobre la laja había un [árbol< colgaba una bonita rama < de la rama colgaban bonitos los nidos de los conotos. Muchos conotos entraban, salían. Ahora los muchachos miraban un nido. En la puerta del nido el padre conoto asomaba su cabeza.

- Llegamos- dijo Iureke- ¿Vives aquí, sobre el río? Dinos como mataron a Hui 'io, la madre de los peces.

El conoto contestó - Tiwa, tiwa. Así cantaban. Así cantaban también los conotos de ahora. Puedes oírlos.

- ¿Qué dices?- preguntó Iureke.

- Tiwa, tiwa, - cantó otra vez.

- No entiendo la lengua de los conotos- dijo Iureke

Shikié 'mona dijo: - Yo sí entiendo. Él dice Tiwa, tiwa (flechando). 
Así supieron los muchachos cómo su madre había muerto. Cuando volvieron a casa de Manawa no entraron. Pegaron sus orejas contra la puerta desde afuera, para oír nada más.

- Se han zambullido al río- decía Kawao-. No obedecen, sólo fastidian, sólo hacen preguntas.

- Ahora son grandes. Si descubren la verdad, nos van a matar. Si vuelven, tú vas a matarlos. Con tijeras cortarás sus cabezas- dijo Manawa.

- ¿Cómo puedo hacerlo? Yo los críe ahora son mis hijos- contestó la rana.

- Ahora voy a buscar medikiu (sal vegetal, ceniza de palo) para salarlos. Vas a preparar su caldo. Los vas a cocinar sabroso. Ten lista esa comida. Voy a buscar medikiu, luego volveré, tendré hambre- dijo jaguar. Salió a buscar la ceniza para salar el caldo de carne de muchachos.

- Bueno- dijo Kawao.

- Ahora los muchachos entraron por otra parte.

- Llegamos -dijeron-. Hemos nadado ahora tenemos hambre. ¿Dónde está nuestra comida?

- No hay comida - contestó la rana.

- Tenemos hambre - dijeron-. Danos casabe. Dinos cómo cocinas.

- Nada. No obedecéis- contestó la rana.; les dio una paliza y los echó.

- Bueno, nos vamos- dijeron.

- Los muchachos salieron; ahora se pusieron de acuerdo.

- ¿Cómo haremos?- dijo uno.

- Descubriremos el secreto- dijo el otro. Robaremos aquello; no queremos ser cocidos en aquel caldo.

- Bueno -dijo Iureke-. Vamos a volver a pedir nuestra comida. Ella nos echará. Me voy a esconder en la casa. Tú saldrás, armarás alboroto afuera. Ella va a creer que estamos jugando. Yo estaré mirando, escondido adentro, en el techo. Así vamos a saber.

Entraron; pidieron casabe; Kawao los echó. Shikié 'mona salió solo, Iureke se escondió en el techo. Quería descubrir el secreto de la rana. Cogió uno de sus ojos y se lo pegó en la nuca para ver hacia atrás. Kawao oyó el alboroto afuera que armaba Shikié 'mona. Parecían dos muchachos jugando. Era uno nada más. Bueno salieron, pensó Kawao. Ahora están peleando; voy a hacer casabe; apuraré antes de que vuelvan a molestar. Ahora miró el budare; allí estaba el reflejo de Iureke. Entornó los ojos hacia el techo: allí estaba Iureke.

- ¿Qué haces trepado en los horcones? No has salido a jugar.

- No puedo- dijo-Iureke- perdí un ojo, no veo bien, no puedo caminar. No voy a mirarte, me voy a voltear hacia el techo.

- Voltéate pues - dijo la mujer-; no vayas a mirarme- le dijo.

- Bueno- contestó.

El muchacho se volteó.

- No veo nada - dijo-, cocina ahora; tenemos hambre. Él veía todo por el ojo que tenía en la nuca; así la engaño. Ella abrió la olla, sopló fuego debajo del 
budare. Brillo muchísimo debajo del budare. El ojo de atrás de Iureke quedó encandílalo; no vio más nada.

Ahora Shikié 'mona se acercó a la puerta.

- Ahora quiero entrar- dijo.

La comida estaba lista. Kawao sacó la lengua de prisa, recogió el fuego, se lo tragó, lo escondió en su barriga.

- Entra- le dijo ahora a Shikié 'mona-. Vuélvete- le dijo a Iureke.

El muchacho se quito el ojo encandilado de la nuca; se lo colocó otra vez en la frente. Cuando volvió a su lugar, vio bien. Vio el mañoco tostado, listo para comer.

- ¿Cómo hiciste esta comida? - preguntaron a hora los muchachos-. Danos un poquito para probar.

Kawao les cayó a palos. Quería comer sola, tranquila. Luego comió sin darles nada. Shikié 'mona habló bajito con su hermano.

- ¿Qué pasó? - le preguntó.

- Descubrí aquello- contesto Iureke. Brilla, brilla como el sol. Es bonito, bonito.

- Vamos a robar - dijeron-. Vamos a quitarle aquello.

Ahora se acercó la mujer con las tijeras.

- Tenéis pelo largo, muchachos; acercáos, voy a cortarlo.

- Bueno, madre - contestaron los muchachos y se acercaron, tranquilos.

Ahora no hablaban, estaban mansitos. La rana no quería cortarles el cabello, quería corta cabezas nada más. Empezó cortando cabellos; primero le dio lástima, su mano temblaba. Después pensó: Mi marido me dio una orden; volverá, tendrá hambre. Pedirá su caldo de carne. Abrió las tijeras en el cuello de Shikié 'mona. Iureke saltó, arrancó las tijeras, cayó sobre la rana. Ahora los dos le daban puntapiés, tijeretazos, le apretaban el vientre, le abrían la boca.

- iVomita! iSaca aquello de tu barriga! - gritaban los dos.

Empezó Kawao a toser, a escupir, se atragantó, se ahogó. Ahora el fuego se enredo en su garganta, se estancó, no pudo salir. Los muchachos apretaban y nada.

- iEscúpelo! iVomítalo! -gritaban, dándole patadas y tijeretazos.

Tosía, no podía escupir. La bola de fuego llegaba a su garganta, se hinchaba, se deshinchaba, no quería salir. 
- iEscúpelo! iVomítalo! -gritaban.

Shikié 'mona rajó la boca de la rana. El fuego brotó, quemó a la rana en la espalda, rodó al suelo. Iureke brincó, la agarró.

- iEscupiste! - gritaban-. iVomitaste! - gritaban.

Por eso las ranas de ahora, que son nietas de Kawao, tienen espaldas arrugadas y bocas anchas. Tienen una bola en la garganta: se hincha se deshincha...

Por la rajadura de su boca, colgaba la cabeza de Kawao.

Ellos jalaron un poco: se desprendió la cabeza. Así murió aquella rana.

- Con tijeras cortarás sus cabezas. Como dijo Manuwa, hicimos- dijeron los muchachos, y soltaron la carcajada.

- A preparar el caldo, a cocinar sabroso; ten lista esa comida. Como dijo Manuwa, ahora vamos a hacer- dijeron y carcajada.

Trozaron la rana. Soplaron el fuego debajo de la olla. Cogieron la cabeza, en el fondo la pusieron y por encima los otros trozos; ahora, mucho ají.

Ahora cantó la olla; en el caldo nacieron burbujas, cuando los muchachos cocinaron. Cuando llegó Manuwa, oyeron pasos en el camino. Saltaron de prisa, escondieron el fuego. Buscan adonde:

- ¿Aquí? ¿Allí? No, allá. Aquí no sirve.

Había dos palos detrás de la casa. Wi'shu es el nombre de uno; Kumnuatte, el nombre del otro palo. Lo escondieron. Iureke escondió una mitad en wi'shu. Shikié 'mona la otra mitad en kumnuatte. Siempre lo recordamos, cuando queremos fuego nuevo. Tomamos wi'shu, kumnuatte, frotamos uno contra otro, llamando, llamando: enseguida el fuego brota, brilla. Esos dos muchachos guardaron aquello para nosotros, escondieron el fuego en dos palos, al principio. Por eso ahora la gente come sabroso.

\begin{tabular}{|l|l|l|l|l|l|}
\hline \multicolumn{2}{|l|}{ Personajes } & Par inicial & Mediador & Héroe & Oposición \\
\hline Humanos & $\begin{array}{l}\text { No } \\
\text { humanos }\end{array}$ & $\begin{array}{l}\text { 1)Kawao-Manawa } \\
\text { 2)Shikié'mona- }\end{array}$ & $\begin{array}{l}\text { Agua- solución } \\
\text { Palos: wi'shu, } \\
\text { kumnatte- } \\
\text { fuego }\end{array}$ & $\begin{array}{l}\text { Los hermanos } \\
\text { Shikié 'mona- } \\
\text { Iureke }\end{array}$ & $\begin{array}{l}\text { Vida-muerte } \\
\text { agua-tierra } \\
\text { crudo-cocido } \\
\text { salado-sin sal }\end{array}$ \\
\hline $\begin{array}{l}\text { Kawao } \\
\text { Manawa }\end{array}$ & $\begin{array}{l}\text { Rana } \\
\text { Shikié'mona } \\
\text { Iureke }\end{array}$ & $\begin{array}{l}\text { Jaguar } \\
\text { Hui'io }\end{array}$ & & & \\
\end{tabular}

\subsubsection{El origen del fuego- baja guajira}

En un principio los hombres no conocían el fuego. Eran seres imperfectos que comían cosas crudas, tanto carnes como tubérculos, raíces y frutos, silvestre. Ningún alimento vegetal era pasado por el fuego, ni calentado ni cocido, nada preparado se comía.

La carne no la ahumaban, no la asaban; sino que la hacían cecina, la tendían al sol y la consumían seca. 
La triste suerte de los primeros hombres a causa de su imperfección era igual a la de los animales. Unos vivían metidos en los troncos, en los huecos, en las cuevas; otros tenían ranchos para abrigarse, pero sin fuego para calentarse ni lumbre para ahuyentar el miedo que emergía del fondo de las noches. Sólo Maleiwa poseía el fuego en forma de piedras encendidas que celosamente guardaba en una gruta fuera del alcance de los hombres.

Maleiwa no quería entregar el fuego a los hombres porque éstos eran faltos de juicio, y en vez de hacer buen uso de él podían emplearlo para sus maldades; quemar sus ranchos, incendiar los montes, quemar a las criaturas vivientes y apurarse calamidades. Por eso los preservó de su uso.

Pero sucedió una vez, que estando Maleiwa sentado junto al fuego (Ootorojoshi) calentando el cuerpo al calor de la fogata; vio venir hacia él, un joven aterido de frío, llamado Junuunay.

Maleiwa, al verlo, se indignó grandemente.

¿Qué venís hacer, intruso? ¿No sabéis que este sitio está vedado a todo acceso? ¿A caso venís a perturbar mi tranquilidad y a colmar mi paciencia? $Y$ Junuunay respondió con actitud suplicante:

No, venerable abuelo. Sólo vengo a calentar mi cuerpo junto a vos. Tened clemencia para mí que no he querido ofenderos. Amparadme de este frío que me hiela, que me puya la carne y me llega hasta los huesos. Tan pronto entre en calor me marcharé.

Así decía Junuunay escondiendo su intención.

Aquel joven audaz, para convencer a Maleiwa se valió de mil artimañas. Hizo crujir sus dientes. Erizó los poros de su cuerpo como carne de gallina muerta, tembló como machorro, frotó sus manos. Hasta que por fin, Maleiwa, compadecido, lo aceptó. Pero el Gran Padre no le quitaba la vista de encima, porque tenía sus reservas respecto a la habilidad tan candorosa de aquel extraño personaje, que más inspiraba admiración que desdén.

...Y ambos comenzaron a frotarse las manos y a darse calor en todo el cuerpo.

Las llamas de aquel fuego eran intensamente bellas, resplandecían a lo lejos como los fulgores áureos de las estrellas, como el Skemeche Aitu'u, como las brasas del cielo.

Junuunay se llenó de coraje y quiso conversar con Maleiwa para distraerlo, pero éste permaneció callado sin hacer caso a las palabras del intruso. Pero un rumor de viento hizo que Maleiwa voltease la cara hacia atrás para mirar y cerciorarse bien del pequeño ruido que se avecinaba. Era algo así como si fuesen pasos cautelosos que estrujarán la hojarasca del paraje.

Aquel instantáneo descuido lo aprovechó Junuunay. Cogió de la fogata dos brasas encendidas y rápidamente las metió en un morralito que llevaba oculto bajo el brazo. Con las mismas se dio a la fuga, y se escurrió por entre la maleza que circuían la gruta.

Consumado el robo, y burlado así el Gran Maleiwa, éste se dio en perseguirlo para castigarlo.

Maleiwa decía: - iMe ha engañado el muy bribón! Le castigaré dándole el suplicio de una vida inmunda. Le haré vivir en los muladares, en los estercoleros rodando bolas de excremento... Y diciendo esto, corrió tras el ladrón. 
Junuunay, huía desesperado, pero sus pasos eran tan lentos y cortos que casi no avanzaba el menor trecho. $Y$ en este trance difícil, quiso emplear de nuevo su escurridiza habilidad para salvarse.

Llamó en su auxilio a un joven cazador llamado Kenaa a quien rápidamente le entregó una brasa para que la escondiera.

Kenaa tomó la preciosa joya incandescente y se alejo con ella sin ser visto. El sol le ocultó de la vista Maleiwa, pero siempre fue descubierto cuando llegó la noche y trataba de esconderse entre las matas.

Entonces Maleiwa, para castigarlo lo convirtió en cocuyo nocturnal, que en las noches oscuras de invierno emite su luz intermitente cuando vuela.

Junuunay, en su desesperación, encontró a su paso a Jimut el Cigarrón, y le dijo:

- Amigo mío, Maleiwa me persigue porque le he robado el fuego para dárselo a los hombres. Tomad esta brasa que me queda, huid con ella y escondedla en un sitio bien seguro, que quien posea esta joya será el más afortunado de los hombres: sabio y grandioso. Dicho esto, Jimut tomó la brasa y rápidamente la metió dentro de un palo de caujaro, luego la pasó a un olivo, después a otro palo, y así se extendió y multiplicó por todas partes, hasta que los hombres la encontraron una vez por medio de un niño llamado Serumaa. Este niño, mientras se divertía en saltar y jugar por entre los montes, iba señalando a los hombres los palos en donde Jimut había depositado el fuego.

Aquel niño no sabía hablar solo sabía decir: iSkii! ...iSkii...! iiSkii...!! iFuego...! iiFuego...!! iiFuego...!!

Los hombres de entonces se apresuraron a buscar el fuego, pero ellos no podían encontrarlo y tampoco lo sabían obtener. $Y$ así registraron todos los palos, los troncos y nada pudieron conseguir. Practicaron mil maneras y nada pudieron obtener. Entonces vieron a Jimut que perforaba un palo, y siguiendo el ejemplo de éste, taladraron y frotaron con sus manos dos varitas de Caujaro, y al punto surgió el fuego que iluminó el corazón de los montes y encendió de alegría el Espíritu de los hombres.

Desde entonces el fuego lo destinaron a sus servicios.

Ya los hombres no sintieron más temor, ni volvieron a sufrir los rigores de las noches frías.

En cuanto al niño Serumaa, lo convirtió Maleiwa en pajarillo que salta de rama en rama diciendo: iSkii! ...iSkii...! iiSkii.!! Su voz natural.

Desde entonces, se moteja Sikiyuu al Serumaa.

Esto aconteció después que Maleiwa convirtió a Jununay en escarabajo y lo condenó a vivir en las inmundicias por haber robado el fuego.

Desde entonces el escarabajo, vive y se alimenta de excrementos. $Y$ en castigo de su atrevimiento, quedó impreso en su cuerpo la mancha de su robo, o sea, las manchas brillantes que llevan en sus patas los escarabajos.

\begin{tabular}{|l|l|l|l|l|l|}
\hline Personajes & Par inicial & Mediador & Héroe & Oposición \\
\hline Humanos & $\begin{array}{l}\text { No } \\
\text { humanos }\end{array}$ & $\begin{array}{l}\text { Maleiwa- } \\
\text { Junuunay }\end{array}$ & $\begin{array}{l}\text { Cigarrón- } \\
\text { solución } \\
\text { Palo } \\
\text { caujaro- fuego }\end{array}$ & Junuunay & $\begin{array}{l}\text { Cocido-crudo } \\
\text { Frío-calor } \\
\text { Animal-humano } \\
\text { Cielo-tierra }\end{array}$ \\
\hline $\begin{array}{l}\text { Maleiwa } \\
\text { Junuunay } \\
\text { Kenna }\end{array}$ & Jimut & & \\
\hline
\end{tabular}


De estos primeros cuatro mitos, todos de etnias venezolanas, podemos concluir que, en todos los casos los seres humanos en sus inicios no conocían el fuego y por ello debían comer cruda su comida, fuese ésta de origen vegetal o animal; incluso hay en uno de los mitos en el que se hace referencia explícita a que eran imperfectos, como animales. Dándole así al conocimiento del fuego y al hecho de cocinar los alimentos un rango civilizador y diferenciador del ser humano, de los animales.

Otro aspecto interesante de resaltar es el hecho de que en todos los casos el fuego, su conocimiento, pertenecía solo a una persona (en dos casos mujeres y otros dos hombres) y luego de ser robados es que se hacen uso de él todos los habitantes humanos de la selva. Se torna curioso que en los casos en que son mujeres las poseedoras del secreto, lo guardan en sus barrigas, en sus entrañas, sitio en el que por lo general las mujeres anidan la vida. Sin embargo, en los mitos en los que los hombres son los conocedores el fuego está en tizones o piedras, pero definitivamente fuera del cuerpo de sus dueños.

Un elemento común en tres de los mitos, hasta aquí presentados es que el fuego luego de robado es escondido en palos y que para volver a obtenerlo basta con frotar entre sí a dos ramas de alguno de los tipos de árbol en los que fue escondido el fuego; otro factor que se repite es el hecho que hay dos mediadores uno que permite resolver el conflicto presentado en el mito y que por lo general es un elemento de la naturaleza (un árbol, el agua, un cigarrón), y otro mediador que permite obtener el fuego una vez que han despojado a su dueño, dueña inicial, para mitigar el frío, iluminar la oscuridad de la noche y cocer los alimentos.

Otro aspecto interesante de los mitos de las etnias venezolanas es que en ellos se presentan técnicas culinarias: asar, cocer en olla (caldo), hornear, secar al sol (cecina); además del saldo de las carnes a pesar de no conocer la sal marina sino a través de la ceniza y de una hierba en particular (ver M3). En los mitos trabajados aquí se hace mención a distintos productos que conformarían la dieta de nuestros grupos originarios, mas en dos de ellos se pone a la carne humana como elemento comestible aunque sea en uno de ellos por el dueño del fuego, Jekunu Arotu (M1) que se devela como no humano y en M3 con Manawa (jaguar) quien desea salar y comer el caldo de sus hijos.

Pero en estos mitos no se presenta de forma exclusiva el origen del fuego, ya que en M3 se explica el por qué las ranas que son nietas de Kawao tienen la espalda arrugada y la boca grande, así como en M4 se explica por qué los escarabajos viven en la inmundicia y sus patas son brillantes y el origen de los pájaros Ski, Skii y su forma de cantar.

\subsection{Brasileños}

\subsubsection{Kayapó-Gorotire: origen del fuego.}

Por haber localizado una pareja de guacamayos que anidaban en la cima de una roca abrupta, un indio lleva a su cuñado joven, llamado Botoque, para que lo ayude a 
capturar los hijuelos. Le hace trepar una escala improvisada, pero llegada la altura del nido, pretende no ver en él más que dos huevos (no está claro si miento o dice la verdad). Su cuñado los exige; al caer, los huevos se vuelven piedras que le hieren la mano. Furioso, retira la escala y se va, sin comprender que los pájaros estaban encantados (oaianga).

Botoque sigue prisionero varios días en lo alto de la roca. Adelgaza; el hambre y la sed lo obligan a consumir sus propios excrementos. Distingue al fin a un jaguar manchado portador de un arco, flechas y todas clases de piezas de caza. Quisiera pedirle socorro pero el miedo lo hace enmudecer.

El jaguar nota la sombra del héroe en el suelo; intenta vanamente atraparla, levanta los ojos, indaga, advierte la escala, invita a Botoque a descender. Aterrado, éste vacila largo tiempo; finalmente se decide y el jaguar amistoso le propone que se le suba al lomo y vaya a su morada a comer carne asada. Pero el joven ignora el significado de "asada" porque en aquel entonces los indios no cocían en el fuego y se alimentaban de carne cruda.

En casa del jaguar el héroe ve un gran tronco de jatoba que se consume; al lado, montones de piedra como las que utilizan hoy los indios para construir sus hornos (ki). Por primera vez come carne cocida.

Pero la esposa del jaguar (que era india) no le gusta el joven indio, al que llama meon-kra-tum ("hijo extraño, o abandonado"); con todo el jaguar que o tenía hijos, decide adoptarlo.

Todos los días el jaguar sale de caza y deja al hijo adoptivo con su esposa, que le testimonia creciente aversión, no le da de comer más que carne vieja y endurecida, y hojas. Cuando el chico se queja, le araña el rostro y el pobrecillo tiene que refugiarse en el bosque.

El jaguar reprende a su esposa pero en vano. Un día le da a Botoque un arco flamante y flechas, le enseña a usarlo y le aconseja usarlo contra su madrastra llegado el caso. Botoque la mata de un flechazo en pleno pecho. Aterrerorizado huye llevándose sus armas y un pedazo de carne asada.

Llega a su pueblo en plena noche, encuentra a tientas la yacija de su madre, se da a conocer no sin esfuerzo (pues lo creían muerto); relata su historia, reparte la carne. Los indios deciden apoderarse del fuego.

Cuando llegan a donde el jaguar no hallan a nadie; y como la esposa está muerta las piezas de caza de la víspera siguen crudas. Los indios las asan y se llevan el fuego. Por vez primera pueden alumbrarse de noche en el pueblo, comer carne cocida $y$ calentarse junto al hogar.

Pero el jaguar, furioso por la ingratitud del hijo adoptivo que le ha robado "el fuego y el secreto del arco y las flechas", quedará lleno de odio hacia todos los seres y en 
especial hacia el género humano. Sólo el reflejo del fuego brilla aún en sus pupilas. Caza con los colmillos y come la carne cruda, pues ha renunciado solemnemente a la asada.

\begin{tabular}{|l|l|l|l|l|l|}
\hline Personajes & Par inicial & Mediador & Héroe & Oposición \\
\hline Humanos & $\begin{array}{l}\text { No } \\
\text { humanos }\end{array}$ & Botoque-jaguar & Guacamayos & Botoque & $\begin{array}{l}\text { Cocido-crudo } \\
\text { Animal-humano }\end{array}$ \\
\hline $\begin{array}{l}\text { Cuñado } \\
\text { Botoque } \\
\begin{array}{l}\text { Esposa del } \\
\text { jaguar }\end{array}\end{array}$ & Jaguar & & & & \\
\hline
\end{tabular}

\subsubsection{Tukuna: el yerno del jaguar.}

Un cazador extraviado llega a la residencia del jaguar. Las hijas de éste le invitan a entrar, no sin explicarles que el mono que perseguía es su animal familiar. Cuando vuelve el jaguar, olfateando carne humana, su mujer esconde al cazador debajo del techo. El jaguar traía una caetetu para la comida. Luego de hacerse al hombre tembloroso de miedo, y de haberlo lamido de la cabeza a los pies, la fiera se quita la piel, adopta forma humana y charla sin ceremonias con su invitado esperando la hora de la comida.

Sin embargo la mujer del jaguar advierte en secreto al cazador que la carne será muy picante y que al comer no deberá parecer incomodado. Efectivamente la comida abrasaba la boca pero el hombre consigue ocultar su sufrimiento, no sin esfuerzo. El jaguar está encantado, lo felicita y lo pone en camino a su pueblo.

Pero el cazador se pierde, retorna a la casa del jaguar, que le indica otro camino; vuelve a perderse y regresa. Las hijas del jaguar le proponen matrimonio; el hombre acepta, el jaguar lo permite.

Un día mucho más tarde, volvió a visitar a los suyos. Su madre advierte que se ha tornado arisco y que su cuerpo empieza a cubrirse de manchas, como el pelaje del jaguar. Acabo de pintarlo con carbón pulverizado. Él corrió a la selva, donde sus mujeres humanas lo buscaban por todas partes. Nunca más se volvió a ver.

\begin{tabular}{|l|l|l|l|l|l|}
\hline Personajes & Par inicial & Mediador & Héroe & Oposición \\
\hline Humanos & $\begin{array}{l}\text { No } \\
\text { humanos }\end{array}$ & Cazador-jaguar & $\begin{array}{l}\text { Hijas-esposa } \\
\text { del jaguar }\end{array}$ & Cazador & $\begin{array}{l}\text { Cocido-crudo } \\
\text { Animal-humano }\end{array}$ \\
\cline { 1 - 1 } $\begin{array}{l}\text { Cazador del } \\
\text { Hijas del } \\
\text { jaguar }\end{array}$ & Jaguar \\
$\begin{array}{l}\text { Madre del } \\
\text { cazador }\end{array}$ & & & & \\
\hline
\end{tabular}

\subsubsection{Tukuna: origen del fuego y de las plantas cultivadas}

En otro tiempo los hombres no conocían ni la mandioca dulce ni el fuego. Una vieja había recibido, de las hormigas, el secreto de la primera, y su amigo el pájaro nocturno (un chotocabras, Caprimulgus sp) le procuraba el fuego (que llevaba 
escondido en el pico) para que cociera la mandioca en vez de recalentarla exponiéndola al sol o guardándosela en la axila.

Los indios encontraron excelentes las galletas de la vieja y quisieron saber cómo las preparaba. Ella les contestó que simplemente las pone a cocer al calor del sol. Divertido por esa mentira, el pájaro se echa a reír y se le ven salir llamas de la boca. Se la abren a la fuerza y le arrebatan el fuego. Desde aquel día los chotocabras tienen el pico largo.

\begin{tabular}{|l|l|l|l|l|l|}
\hline Personajes & Par inicial & Mediador & Héroe & Oposición \\
\hline Humanos & $\begin{array}{l}\text { No } \\
\text { humanos }\end{array}$ & $\begin{array}{l}\text { Vieja- } \\
\text { Chotocabras }\end{array}$ & Chotocabras & & $\begin{array}{l}\text { Cocido-crudo } \\
\text { Animal-humano }\end{array}$ \\
\cline { 1 - 3 } & $\begin{array}{l}\text { Vieja } \\
\text { Otros indios }\end{array}$ & Chotocabras & & & \\
\hline
\end{tabular}

\subsubsection{Bororo: origen del fuego}

En otro tiempo el mono era como el hombre: no tenía pelo, circulaba en piragua, comía maíz y dormía en hamaca.

Un día, pues, el mono navegaba en compañía del prea (Cavia aperea) y le inquietó verle roer ávidamente el maíz que estaba amontonado en el fondo de la piragua, pues volvían de su plantación: "detente -le dice-, vas a perforar el casco, entrará el agua, nos ahogaremos, no escaparás, los peces pirañas te comerán". Pero el prea sigue royendo, y ocurrió lo que el mono había previsto. Como sabía nadar muy bien, consiguió encajar la mano en las branquias de una piraña, y blandiendo su presa ganó orilla.

Poco después se encuentra con el jaguar, maravillado al ver el pez y le pide que lo invite a comer. "Pero ¿dónde está el fuego?", pregunta. El mono señala al jaguar el sol que desciende hacia el horizonte bañando la lejanía con una luz rojiza. "Allí, ino lo ves? Ve a buscarlo".

El jaguar va muy lejos y vuelve, confesando su fracaso. "Pero no -replica el mono-, iMíralo, rojo y ardiente! iCorre, corre pues! iY ahora ve hasta el fuego para que podamos cocer nuestro pescado!" y el jaguar echa a correr.

Entonces el mono inventa la técnica para producir fuego haciendo girar un bastón apoyado en otro, y que los hombres aprendieron después de él. Enciendo el fuego, asa el pescado, devora todo menos las espinas. Después sube a un árbol - hay quien dice que era una jatoba- y se instala en la punta.

Cuando el jaguar regresa con los pies maltrechos, comprende la mala pasada de que ha sido víctima y se indigna. "Maldito mono, ivoy a matarlo de una dentellada! Pero ¿dónde está?"

El jaguar empieza por comerse los restos del pescado y busca al mono por las huellas, sin éxito. El mono silba y vuelve a silbar. Al fin y al cabo el jaguar lo descubre, pide al 
mono que baje, pero éste se niega, temiendo ser muerto a pesar de las protestas del jaguar. El jaguar provoca entonces un ventarrón que columpia la punta del árbol; el mono se aferra, pronto le faltan las fuerzas y se agarra con una mano. "iVoy a soltarme - le grita al jaguar-, abre la boca!" el jaguar la abre todo lo que puede, y en ella desaparece el mono luego de caer rodando. Llega al vientre de la fiera. Y el jaguar gruñendo y relamiéndose el hocico se interna en el bosque.

Pero las cosas marcha mal para él pues el mono se agita de tal manera en su vientre, que se siente incómodo. Suplica al mono que esté tranquilo: en vano. Por último el mono empuña su cuchillo, abre el vientre del jaguar, sale. Despoja al jaguar agonizante de su piel, la corta en tiras y con ellas se adorna la cabeza. Encuentra otro jaguar, animado de intenciones hostiles. El mono la atrae la atención a su atuendo y, al comprender así que su interlocutor es un matador de jaguares, la fiera se asusta $y$ escapa.

\begin{tabular}{|l|l|l|l|l|l|}
\hline Personajes & Par inicial & Mediador & Héroe & Oposición \\
\hline Humanos & $\begin{array}{l}\text { No } \\
\text { humanos }\end{array}$ & Mono-jaguar & $\begin{array}{l}\text { Agua } \\
\text { Palo }\end{array}$ & Mono & $\begin{array}{l}\text { Cocido-crudo } \\
\text { Caza-siembra }\end{array}$ \\
\cline { 1 - 2 } & $\begin{array}{l}\text { Mono } \\
\text { Jaguar }\end{array}$ & & & & \\
\hline
\end{tabular}

\subsubsection{Ofaié: origen del fuego}

En otro tiempo la madre del jaguar era la dueña del fuego. Los animales se pusieron de acuerdo para robar un tizón. El armadillo lo intenta primero: va a donde la vieja, pretende tener frío, pide y obtiene el permiso de calentarse. Cosquillea a la vieja debajo del brazo para dormirla y cuando siente que se aflojan los músculos coge un tizón y escapa. Pero la vieja despierta, silba para alertar a su hijo el jaguar. Éste atrapa al armadillo y recupera el tizón.

La misma desventura le ocurre al coita, luego al tapir, al mono capuchino, al mono aullador - a todos los animales, a fin de cuentas. Le estaba reservado al prea, animal insignificante, triunfar donde otros fracasaran.

Pero el prea actúa de otra manera. Llega a la residencia del jaguar y no se muerde la lengua: "Buenos días, abuela, ¿cómo estás? He venido por el fuego." Y diciendo esto se apodera de un tizón, se lo cuelga al cuello y se va.

Alertado por el silbido de su madre, el jaguar quiere cortar el camino al prea; éste logra evitarlo. El jaguar se lanza a perseguirlo pero el prea le lleva varios días de ventaja. Al fin lo alcanza, en la otra orilla del Paraná. "Charlemos - le dice el prea al jaguar-. Ahora que has perdido el fuego va a hacer falta que encuentres otro modo de subsistir". Mientras tanto el tizón (aunque lo que sigue sugiere que no era más que un trozo de leño) sigue ardiendo y así se volvía más ligero y fácil de llevar". 
El prea es un animal engañador. Ya lo era en aquella época; por eso supo engañar al jaguar explicándole que ningún alimento era más sano que la carne cruda y sangrante. "Ya entiendo dice el jaguar -, hagamos la prueba"- y da al prea un zarpazo en el hocico, dejándoselo corto, como lo sigue teniendo desde entonces. Persuadido finalmente por el prea (responsable, por lo tanto, del peligro que hoy día representa el jaguar para los hombres) de que existían otras presas, el jaguar le imparte un curso de cocina: "si tienes tiempo cuécela en un horno excavado en el suelo, calentado de antemano, con hojas para proteger la carne y tierra y brasas por encima". Durante esas explicaciones el tizón acaba de consumirse y se apaga.

El jaguar enseña entonces al prea la técnica para obtener fuego por rotación y el prea se echa al mundo encendiendo fuego en todas partes. El fuego se propaga hasta el pueblo, donde su padre y los otros habitantes hacen al prea una recepción triunfal. Entre las matas se ven aún vestigios calcinados de los fuegos del prea.

\begin{tabular}{|l|l|l|l|l|l|}
\hline \multicolumn{2}{|l|}{ Personajes } & Par inicial & Mediador & Héroe & Oposición \\
\hline Humanos & $\begin{array}{l}\text { No } \\
\text { humanos }\end{array}$ & Vieja-prea & & Prea & $\begin{array}{l}\text { Cocido-crudo } \\
\text { Siembra-caza }\end{array}$ \\
\cline { 1 - 2 } Vieja & $\begin{array}{l}\text { Jaguar } \\
\text { Armadillo } \\
\text { Coita } \\
\text { tapir }\end{array}$ & & & & \\
\hline
\end{tabular}

\section{CONCLUSIONES}

Los mitos seleccionados, de entre los que Lévi-Strauss estudió en Mitologías. Lo crudo y lo cocido, se puede establecer que en estos cinco mitos el personaje permanente en ellos es el jaguar, siendo en tres de ellos el dueño del fuego (M5, M6, M9). Una vez más en estos mitos, al igual que en los venezolanos, se presenta al fuego como elemento socializador, civilizador; la diferencia sustancial es que en este conjunto de mitos quienes poseían, no sólo el conocimiento del fuego, sino el uso de instrumentos de caza y cultivo eran los animales, y no los hombres.

En M5 es el cuñado quien deja a la deriva a Botoque quien luego es rescatado; adoptado y protegido por un jaguar; éste le enseña a utilizar el arco, las flechas y a comer carne asada. Este benefactor se ve traicionado por el joven humano y a partir de allí decide renunciar a la carne asada y comienza a cazar con sus colmillos, ya que el arco y la flecha pasaron a ser utensilios empleados por los humanos. En este mito, al tiempo que explican el origen del fuego, explican por qué los tigres tienen los ojos amarillos (resplandor del fuego robado), por qué comen carne cruda.

En tanto que en M6 el joven humano decide quedarse con el jaguar (su suegro) y dejar de lado a los suyos, sin compartir el secreto del fuego y de la cocción de los alimentos. En este mito además se dan a conocer las técnicas de asar y hornear, amen de la explicación de cómo debe prepararse el horno. 
En M7 es una vieja quien conoce el secreto del fuego y todos desean saber el por qué su comida es más sabrosa, es un pájaro quien lo guarda en su interior (el dueño), al igual que en los mitos venezolanos M2 y M3. Pero en éste al tiempo que explican el origen del fuego y cómo los seres humanos se apropiaron de él, narra la explicación del por qué los Chotocabras tienen el pico largo.

Sin embargo, unos y otros están relacionados, si apreciamos M3 y M5 se aprecian más o menos los mismos elementos y relaciones: a) la presencia de 2 huevos, en uno se convierten en niños y en el otro en piedras, b) en ambos casos el jaguar rescata al héroe y lo lleva a casa para adoptarlo y su mujer los cuida, en M3 asume la maternidad y los alimenta, en M5 rechaza al hijo adoptado y no lo alimenta de buena gana, c) en ambos el cazador es el jaguar pero en M5 es el protector y prefiere la muerte de su esposa, quien es humana, a ver que su hijo adoptivo siga siendo maltratado; en tanto que en M3 es la mujer (rana) quien tiende a proteger a los hijos adoptados, pero obedece a su marido y procura su muerte, sin lograrlo, para resguardar el secreto, d) en ambos mitos la mujer del jaguar es asesinada por los hijos adoptivos y se les es arrebatado el fuego. Por lo que bien podrían considerarse como variaciones del mismo mito.

Igualmente ocurre entre $\mathrm{M} 4$ y $\mathrm{M9}$, en ambos se procura engañar al dueño del fuego mediante la treta de hacerse el desvalido, en M4 el dueño es el Maleiwa un anciano y en M9 es la vieja madre del jaguar. Y la secuencia de eventos es similar: a) el fuego es robado por el ardid de hacerse pasar por desvalido y muerto de frío (en M4 es un hombre y en M9 un prea), b) luego de percatarse del robo se emprende la búsqueda y castigo del bribón (en M4 es el mismo Maleiwa y en M9 es el jaguar), c) el fuego no es rescatado y se difunde su conocimiento, d) M9 el jaguar es convencido de comer carne cruda y abandonar el uso del fuego, en tanto que en M4 no hay resignación sino se castiga al ladrón convirtiéndolo en escarabajo y quedando el fuego escondido en dos palos.

Otro elemento interesante al realizar la revisión de estos mitos tiene que ver en el cómo es presentada la risa, ya no como manifestación de alegría, sino como demostración de poder luego de haber dominado al enemigo.

De igual forma se confirma, lo expuesto en la teoría de Lévi-Strauss, que en la estructura del pensamiento mítico se manifiestan las oposiciones, hecho develado en este conjunto de textos, ya que se pone de manifiesto la polarización entre vidamuerte, animal-humano, crudo-cocido, cielo-tierra, y la utilización de herramientas, cocción de los alimentos como hechos culturizantes.

Estas coincidencias en temas, relaciones-oposiciones, personajes, puede deberse a la cercanía geográfica y eje de influencia de la mayoría de las etnias, salvo la guajira cuya distribución queda alejada del macizo guayanés y el amazonas, sin embargo, reafirma un imaginario local, propio de la América, que sin duda se relaciona con el pensamiento mítico universal. 
Podríamos concluir este trabajo afirmando la expresión de Cordón (ob.cit), e indicada en la introducción de esta disertación, cocinar hizo al hombre y marca una caracterización de nuestra alimentación que se ha mantenido en el tiempo ya que se siguen empleando técnicas como asar, hornear, hervido (el caldo silbo e hizo burbujas); así como la utilización de ingredientes como la yuca, el ají, las batatas, carne de casería (la cual si ha sido sustituida por la vacuna y de aves como la gallina y el pollo)

\section{BIBLIOGRAFÍA}

Cartay, Rafael. (1998). Historia de la Alimentación del Nuevo Mundo. Tomo I. Venezuela: Editorial Futuro, C.A.

Cordón, Faustino. (1979). Cocinar hizo al hombre. España: Editorial Tusquets, 3era. Edición.

De Armellada, Cesareo y BENTIVENGA, de Napolitano. (1991). Literaturas indígenas venezolanas. Venezuela: 4ta. Edic., Monte Ávila Editores.

Lévi-Strauss, Claude. (1968). Antorpología Estructural. Argentina: Edt. Universitaria de Buenos Aires. (p.183-210)

Lévi-Strauss, Claude. (1996). Mitologías. Lo crudo y lo cocido. México: Fondo de Cultura Económica.

Paz, Octavio. (1992). Claude Lévi.Strauss o el nuevo festín de Esopo. México: sexta edición, Editorial Joaquín Martínez, S.A.

Shutz, Alfred. (2008). El Problema de la realidad social. Buenos Aires-Madrid: Amorrortu Editores.

\section{Jenny Fraile Velásques}

Jenny Fraile, es egresada del Instituto Pedagógico de Caracas como profesora en Educación Integral, es Especialista en Gerencia Educativa de la Universidad Santa María. Ha realizado estudios de ampliación en el área de lingüística en Universidad Central de Venezuela y culminó en el Pedagógico de Caracas la carga académica de la Maestría en Lingüística. En la actualidad es Doctorando en el Doctorado de Cultura Latinoamericana y Caribeña, en el Instituto Pedagógico de Caracas.

\footnotetext{
' Los mitemas son nudos o haces de relaciones míticas y operan en un nivel superior al parámetro lingüístico. En el nivel más bajo se encuentra la estructura fonológica, en el segundo la sintáctica, común a todos los discursos y el tercer nivel el discurso mítico propiamente dicho con toda su significación.
} 